\title{
Mutant p53 induces EZH2 expression and promotes epithelial- mesenchymal transition by disrupting p68-Drosha complex assembly and attenuating miR-26a processing
}

\author{
Fei-Zhou Jiang ${ }^{1, *}$, Yin-Yan He ${ }^{1, *}$, Hui-Hui Wang ${ }^{2}$, Hui-Lin Zhang ${ }^{1}$, Jian Zhang ${ }^{2}$, Xiao- \\ Fang Yan ${ }^{1}$, Xiao-Jun Wang ${ }^{1}$, Qi Che ${ }^{1}$, Jie-Qi Ke ${ }^{1}$, Zheng Chen ${ }^{1}$, Huan Tong ${ }^{1}$, Yong-Li \\ Zhang $^{1}$, Fang-Yuan Wang ${ }^{1}$, Yi-Ran Li ${ }^{1}$ and Xiao-Ping Wan ${ }^{1,3}$ \\ ${ }^{1}$ Department of Obstetrics and Gynecology, Shanghai General Hospital, Shanghai Jiao Tong University School of Medicine, \\ Shanghai, China \\ ${ }^{2}$ Department of Obstetrics and Gynecology, Shanghai Jiaotong University Affiliated International Peace Maternity \& Child \\ Health Hospital of the China Welfare Institute, Shanghai, China \\ ${ }^{3}$ Department of Obstetrics and Gynecology, Shanghai First Maternity and Infant Hospital, Tongji University School of \\ Medicine, Shanghai, China \\ "These authors have contributed equally to this work \\ Correspondence to: Xiao-Ping Wan, email: wanxp@sjtu.edu.cn
}

Keywords: endometrial carcinoma, p53, EZH2, p68, miR-26a

Received: May 12, $2015 \quad$ Accepted: October 14, $2015 \quad$ Published: November 18, 2015

This is an open-access article distributed under the terms of the Creative Commons Attribution License, which permits unrestricted use, distribution, and reproduction in any medium, provided the original author and source are credited.

\section{ABSTRACT}

The tumor suppressor p53 and the transcriptional repressor Enhancer of Zeste Homolog 2 (EZH2) have both been implicated in the regulation of epithelialmesenchymal transition (EMT) and tumor metastasis via their impacts on microRNA expression. Here, we report that mutant p53 (mutp53) promotes EMT in endometrial carcinoma (EC) by disrupting p68-Drosha complex assembly. Overexpression of mutp53 has the opposite effect of wild-type p53 (WTp53), repressing miR-26a expression by reducing pri-miR-26a-1 processing in p53-null EC cells. Re-expression of miR-26a in mutp53 EC cells decreases cell invasion and promotes mesenchymalepithelial transition (MET). Rescuing miR-26a expression also inhibits EZH2, $\mathbf{N}$-cadherin, Vimentin, and Snail expression and induces E-cadherin expression both in vitro and in vivo. Moreover, patients with higher serum miR-26a levels have a better survival rate. These results suggest that p53 gain-of-function mutations accelerate EC tumor progression and metastasis by interfering with Drosha and p68 binding and pri-miR-26a-1 processing, resulting in reduced miR-26a expression and EZH2 overexpression.

\section{INTRODUCTION}

Endometrial carcinoma (EC) is a common gynecologic malignancy classified into two subtypes, type I and type II [1]. Type I EC occurs in $\sim 85 \%$ of patients and is often estrogen receptor positive with well-differentiated tumors of low grade and good prognosis. Type II EC is a biologically progressive group of ECs that includes papillary serous carcinoma and clear cell carcinoma [2] and accounts for the remaining $15 \%$ of EC cases but is responsible for a disproportionate number of relapses. Patients with type II EC tumors have a 5-year survival rate of only 44\% [3]. Molecular mechanisms explaining the development and progression of type II EC are still unknown.

The tumor suppressor p53 is a transcription factor that inhibits malignant transformation by inducing cell cycle arrest, senescence, and apoptosis [4-6]. p53 is mutated in $50 \%$ of human cancers. The mutant p53 (mutp53) may not only lose its tumor-suppressor functions, it may also acquire oncogenic gain of function (GOF) [7-9]. Integrated genomic characterization of EC tumors revealed that p53 missense mutations were frequent in type II EC, suggesting a role for mutp53 in EC progression [10]. 
Enhancer of Zeste Homolog 2 (EZH2) is the catalytic subunit of the Polycomb Repressive Complex 2 (PRC2), which silences gene transcription through trimethylation of histone $\mathrm{H} 3$ on lysine27 (H3K27me3) [11-13]. EZH2 is often overexpressed in prostate and breast cancers, where it promotes tumor formation and progression and correlates with a poor prognosis [14-16]. EC tumors overexpress EZH2, with higher expression in type II than type I EC (63\% vs 7.6\%) [17], Aberrant p53 status is also associated with EZH2 overexpression [18]; however, the mechanistic links between mutp53 and EZH2 are unknown.

Here, we confirm previous results and identify a novel molecular mechanism by which mutp53 promotes EC invasion and epithelial-mesenchymal transition (EMT). We show that mutp53 interferes with associations between the Drosha complex and p68, leading to attenuation of pri-miR-26a-1 processing and overexpression of its downstream target, EZH2.

\section{RESULTS}

\section{EZH2 and mutp53 are highly expressed in EC specimens}

We examined 124 endometrium specimens: $24.2 \%$ were identified as normal, whereas $48.4 \%$ were type I EC, and $27.4 \%$ were type II EC. The mean age was 51.5 years (range, 26-80 years) in the normal endometrium group, 50.8 years (range, 28-72 years) in the type I EC group, and 54.8 years (range, $40-82$ years) in the type II EC group. A good correlation (75-100\%) between positive immunohistochemistry and p53 mutations was observed in mammary and EC [19]. Of 30 normal endometrial specimens stained by immunohistochemistry (IHC), only one expressed EZH2 at low levels and none expressed p53. In EC tissues, only $10 \%$ of type I tumors had high EZH2 expression whereas $58.8 \%$ of type II tumors

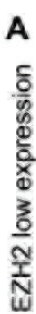
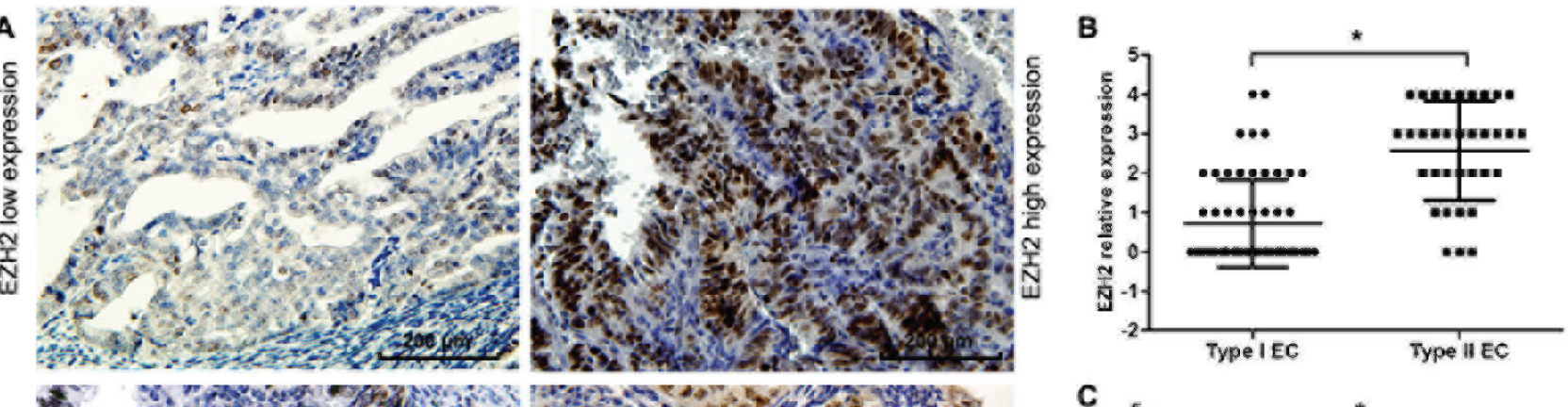

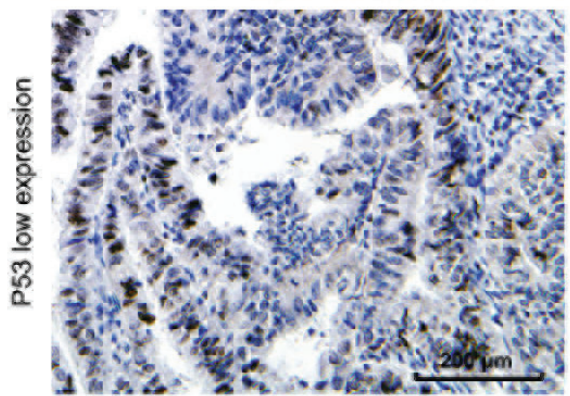

Type I EC

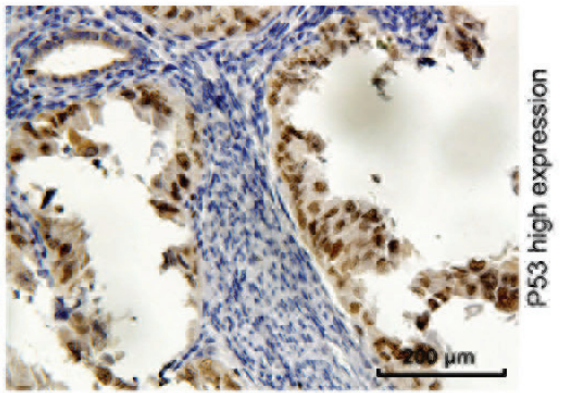

Type II EC

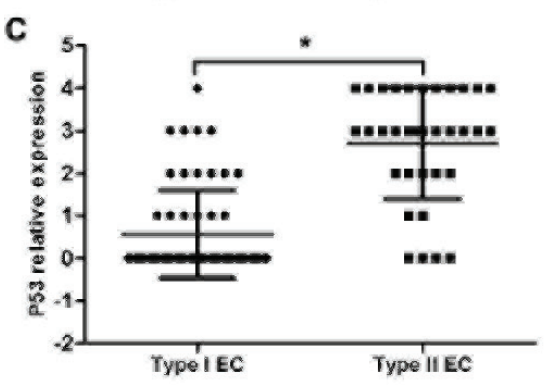

D

\begin{tabular}{cccccc}
\hline & \multicolumn{3}{c}{ EZH2 expression } & & Spearman $r$ \\
\cline { 2 - 4 } & negative & low & high & & \\
\hline P53 expression & 36 & 9 & 2 & 0.000 & 0.739 \\
negative & 2 & 13 & 5 & & \\
low & 2 & 6 & 19 & & \\
high & 2 & & & \\
\hline
\end{tabular}

Figure 1: Mutp53 and EZH2 expression in EC tissues. A. Representative expression of mutp53 and EZH2 in type I EC and type II EC tissues with mutp53 and EZH2 high expression (right panel) and low expresssion (left panel). B. C. Type II EC samples had increased mutp53 and EZH2 expression when compared with type I samples $\left({ }^{*} \mathrm{P}<0.001\right)$. D. EZH2 expression was positively correlated with mutp53 expression in ECs (Spearman correlation $r=0.739$ ). 
expressed high levels of EZH2 (Table 1, $P<0.001$; Figure $1 \mathrm{~A} \& 1 \mathrm{~B}, P<0.001)$. Consistent with its role as an epigenetic modifier and transcriptional regulator, EZH2 expression was predominantly localized in the nuclei of EC cells. Mutp53 shared the same pattern of expression across tissues as EZH2 (6.7\% in type I versus $67.6 \%$ in type II tumors, Figure $1 \mathrm{~A} \& 1 \mathrm{C}, P<0.001)$. Moreover, EZH2 expression was positively correlated with mutp53 expression in type II EC (Spearman correlation $r=0.739$,
Figure 1D). As shown in Table 1, EZH2 expression was higher in cases with a high FIGO stage $(P<0.001)$, a deep myometrial invasion $(P=0.023)$, a high histological grade $(P<0.001)$, and lymph node metastasis $(P=0.002)$. These data suggest a common mechanism underlying EZH2 and mutp53 expression in EC tissues.
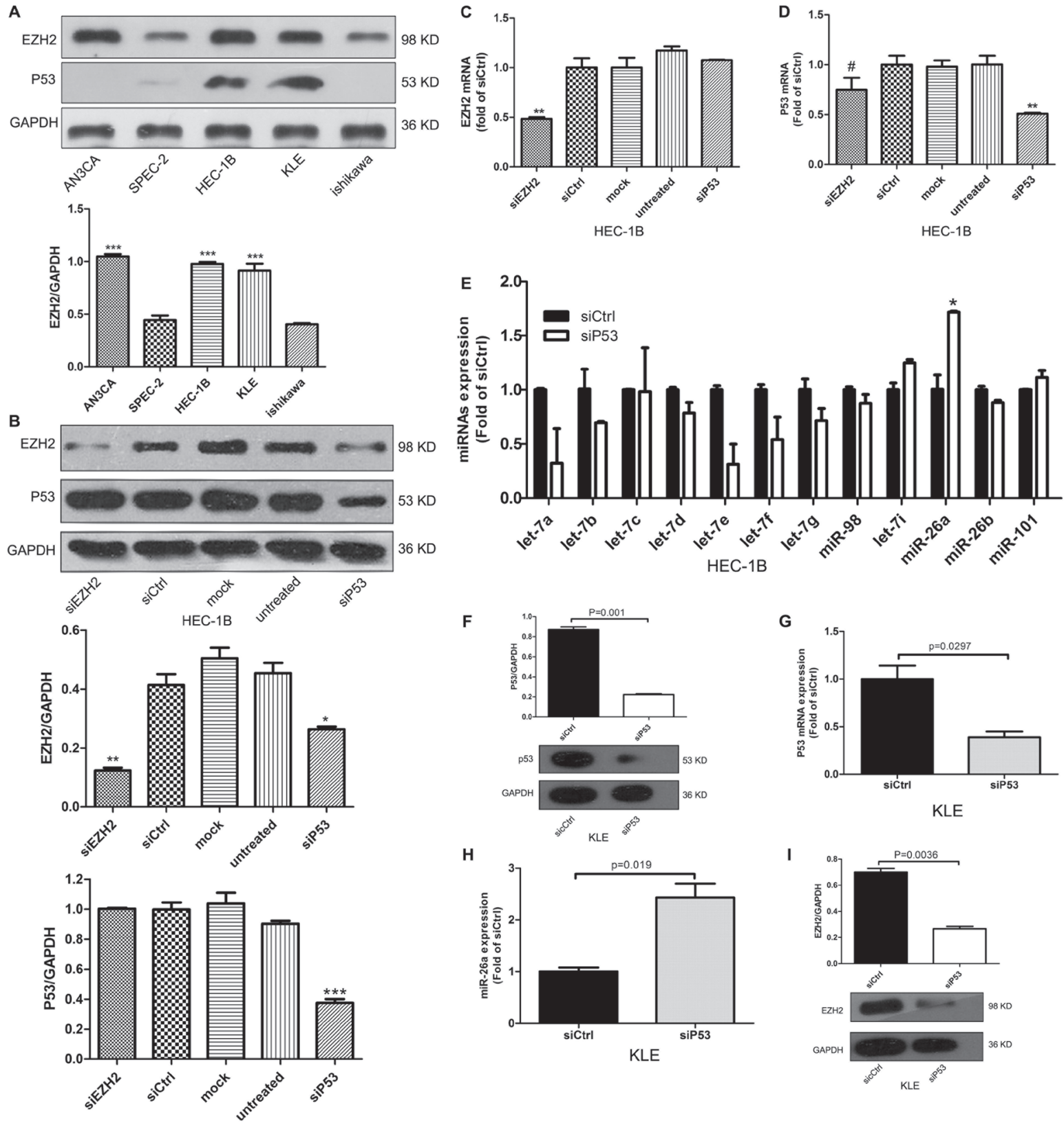

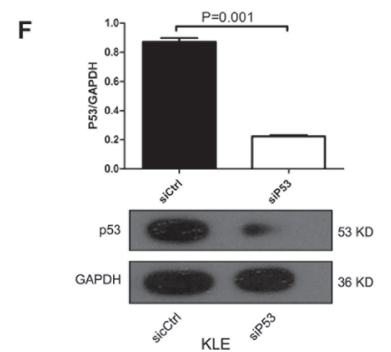

H

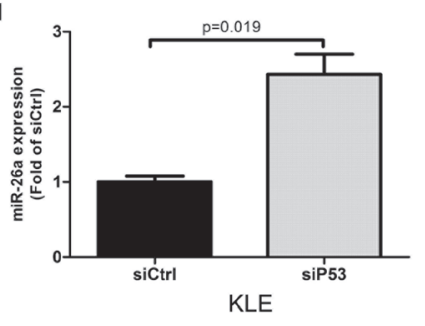

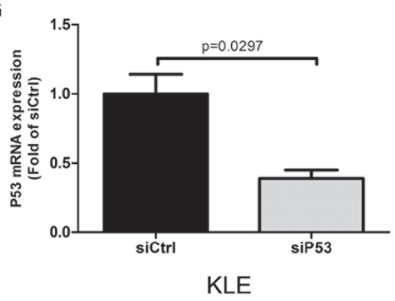

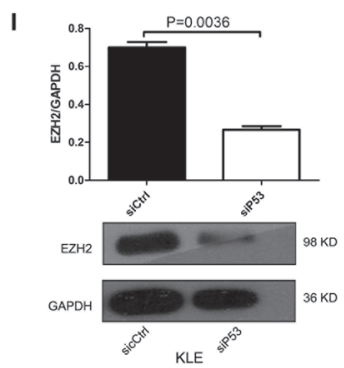

Figure 2: Mutp53 induces EZH2 expression and inhibits miR-26a expression. A. EZH2 expression was examined in five EC cell lines including HEC-1B (p53-R248Q mutation) and KLE (p53-R175H mutation) by western blot (*** $P<0.001)$. B. Mutp53 and EZH2 protein expression after siRNA knockdown of EZH2 or mutp53 $(* P<0.05, * * P<0.01, * * * P<0.001)$. C. EZH2 mRNA expression was not altered $72 \mathrm{~h}$ after siRNA knockdown of mutp53 $(* * P<0.01)$. D. Mutp53 mRNA levels decreased slightly after siRNA knockdown of EZH2 (\#>0.05, $\left.{ }^{* *} P<0.01\right)$. E. miR-26a expression was increased after siRNA knockdown of mutp53 $(* P<0.05)$. F. G. Mutp53 protein and mRNA expression at $72 \mathrm{~h}$ after transfection of siRNA in mutp53 KLE (R175H) cells. H. $\sim$ I. Knockdown of mutp53 induced miR-26a expression and suppressed EZH2 protein expression in KLE cells. 


\section{Mutp53 induces EZH2 expression and inhibits miR-26a expression}

We next examined the expression of EZH2 and p53 in five EC cell lines, including two lines with mutp53: HEC-1B (p53-R248Q) and KLE (p53-R175H). EZH2 was overexpressed in HEC-1B, KLE, and AN3CA cells compared with SPEC-2 and Ishikawa cells (Figure 2A). To investigate the relationship between EZH2 and mutp53, we used siRNA to knockdown mutp53 expression in HEC-1B cells. EZH2 protein expression was decreased with mutp53 knockdown, but EZH2 mRNA expression remained unchanged (Figure 2B \& 2C). In contrast,
siRNA knockdown of EZH2 had no effect on $\mathrm{p} 53$ protein expression, but slightly reduced its mRNA expression (Figure 2B \& 2D, $P>0.05$ ). Therefore, we hypothesized that mutp53 induces EZH2 overexpression through inhibition of a miRNA.

To determine which miRNAs are regulated by mutp53, we used qRT-PCR and the biological predicition software, TargetScan. Down-regulation of mutp53 by siRNA increased miR-26a expression in HEC-1B (Figure 2E) and KLE (Figure 2F, 2G, 2H \& 2I) cells, suggesting that endogenous mutp53 represses miR-26a expression.
A

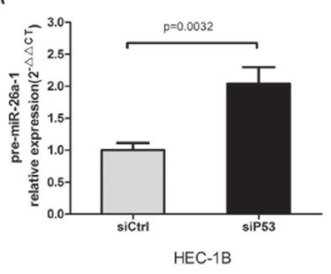

D
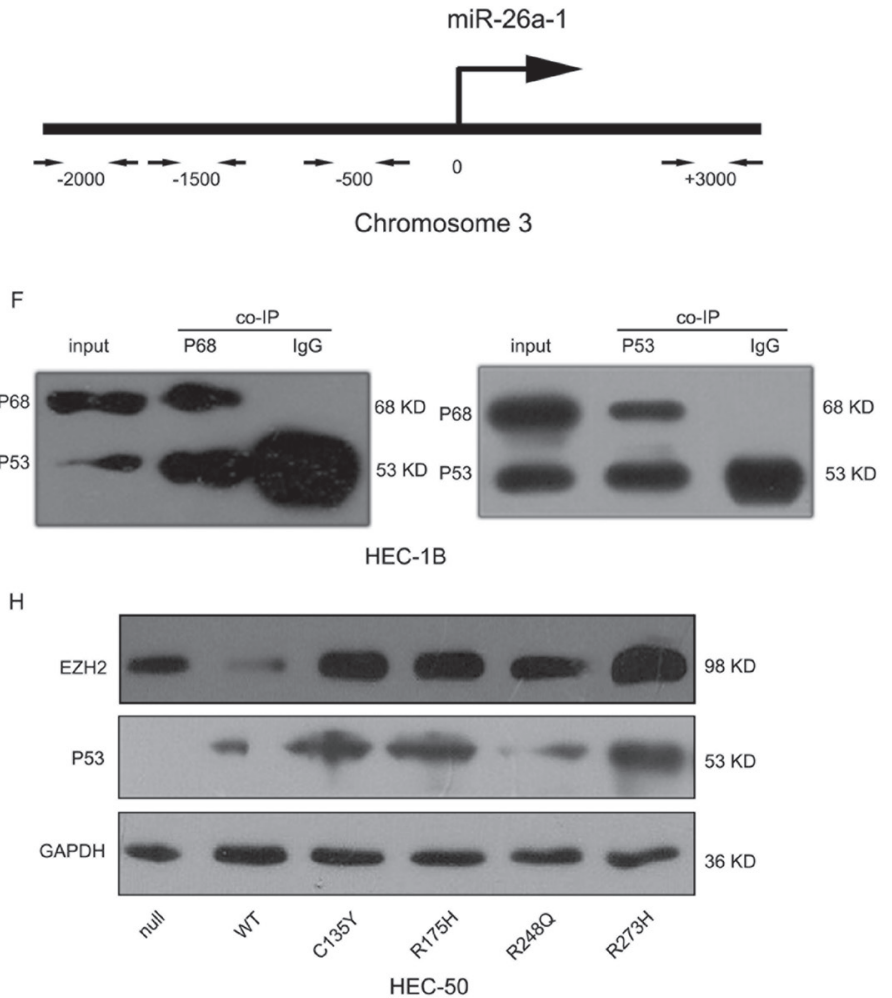

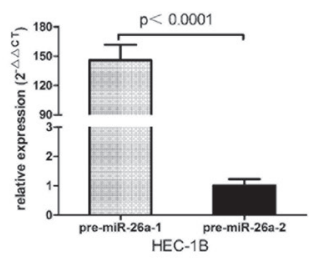

ChIP-qPCR results
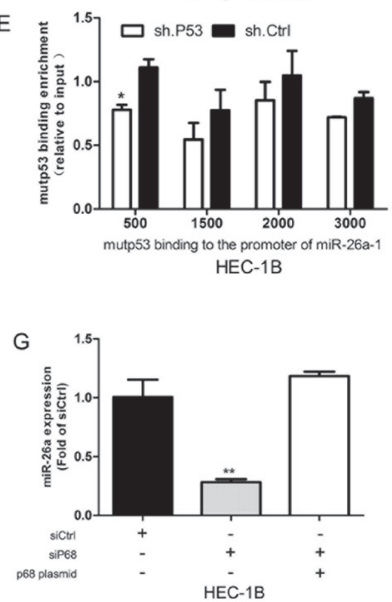

I

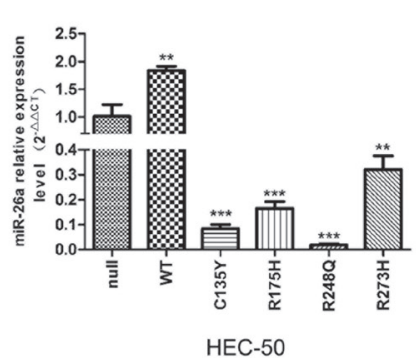

Figure 3: Mutp53 inhibits miR-26a via interactions with p68 and enhances EZH2 expression. A. B. pre-miR-26a-1 and pre-miR-26a-2 expression increased nearly 2-fold in the sip53 group compared with controls. C. pre-miR-26a-1 is expressed nearly 150fold more than pre-miR-26a-2 in HEC-1B cells after silencing mutp53. D. Schematic of the miR-26a-1 regulatory region. E. A summary of ChIP assay results for mutp53 binding in HEC-1B cells transfected with sh.p53 or sh.Ctrl expression plasmid ( $* P<0.05$ ). F. Reciprocal co-IP (co-immuniprecipitation) of p53 and p68. p68 was immunoprecipitated using the p68-specific antibody and p68 and p53 expression detected by Western blot (left panel). p53 was immunoprecipitated using a p53-specific antibody and p53 and p68 expression detected by Western blot (right panel). G. miR-26a expression decreased after p68 knockdown and was rescued by re-expression of p68 $(* * P=$ 0.004). H. p53 and EZH2 protein expression in p53-null HEC-50 cells transfected with different mutp53 expression plasmids. I. miR-26a expression was induced by WTp53 and suppressed by mutp53 $(* * P<0.01, * * * P<0.001)$. 


\section{Mutp53 attenuates pri-miR-26a-1 processing and disrupts p68-drosha complex assembly}

miR-26a is encoded by the two genes, miR-26a-1 and miR-26a-2, which are located on chromosomes 3 and 14, respectively [20]. To elucidate which gene is upregulated after mutp53 inhibition, we examined the expression of miR-26a precursors. After knockdown of mutp53 both pre-miR-26a-1 and pre-miR-26a-2 were increased about 2-fold over the control group (Figure 3A $\& 3 \mathrm{~B}, P<0.01)$. However, the baseline expression of premiR-26a-1 was nearly 150 -fold that of pre-miR-26a-2 in HEC-1B cells (Figure 3C, $P<0.0001$ ). Therefore, the increase in miR-26a is likely due to miR-26a-1 overexpression.

Wild-type p53 (WTp53) activation by genotoxic stress directly induces miR-26a expression via binding of the $-500,-1500$, and -2000 regions of the miR-26a-1 gene [20]. To determine whether mutp53 is able to bind the miR26a-1 gene promoter, we performed a ChIP assay using a p53-specific antibody and a series of primers spanning the upstream region of the gene (Figure 3D). Maximal binding of mutp53 was detected at the -500 region with only a 1.4-fold decrease in sh.p53 (shp53 plasmid carrying small hairpin RNA targeting p53, sh.p53) treated cells compared with controls (Figure 3E, $P<0.05$ ). However, WTp53 bound all three upstream regions in both p53-null HEC50 cells transfected with WTp53 and in wi-38 cells with endogenous WTp53 expression (supplementary figure 1). These results suggest that mutp53 binding to the miR26a-1 gene promoter is impaired and that mutp53 might suppress miR-26a expression by a gain-of-function.

p68 interacts with WTp53, suggesting that it may form a multiprotein transcription regulatory complex [21]. Therefore, we used co-immunoprecipitation experiments to investigate whether p68 interacts with mutp53. As shown in Figure 3F, p68 reciprocally binds mutp53 in HEC-1B cells. Knockdown of p68 decreased miR-26a expression, while re-expression of p68 rescued miR-26a expression (Figure $3 \mathrm{G}, P=0.004$ ). Similar results were found in experiments with p53-null HEC50 EC cells (supplementary figure $2 \mathrm{~A}$ ). To study the effects of several tumor-derived transcriptionally inactive p53 mutants (C135Y, R175H, R248Q, and R273H) on miR-26a expression, we transfected different mutp53 expression plasmids into p53-null HEC-50 cells. While WTp53 induced miR-26a expression, mutp53 suppressed its expression (Figure 3H \& 3I). Conversely, EZH2 expression was downregulated by WTp53 and upregulated by mutp53 (Figure 3H).
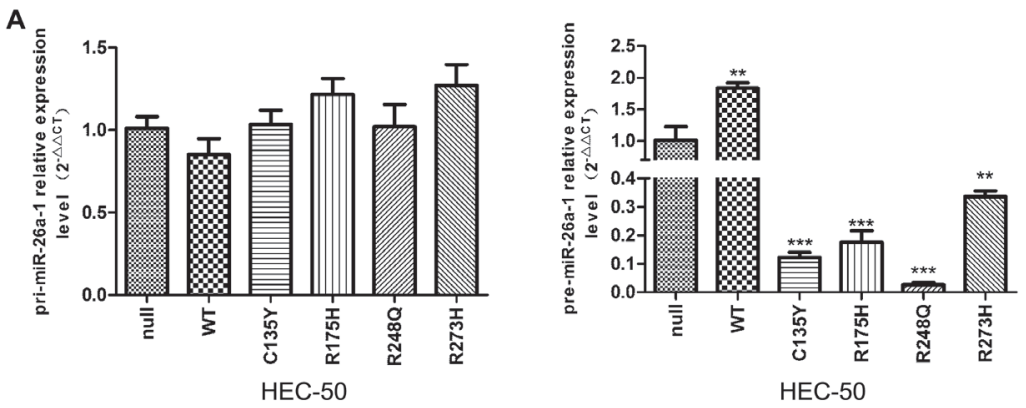

C

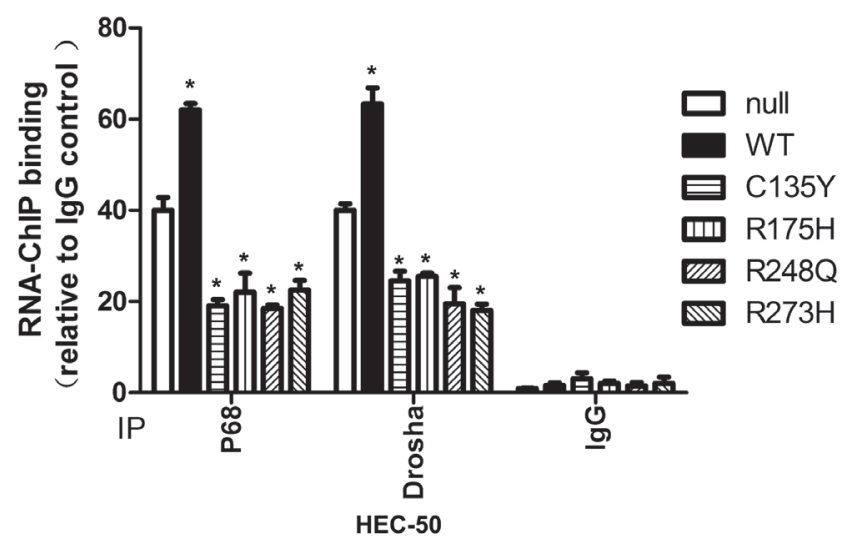

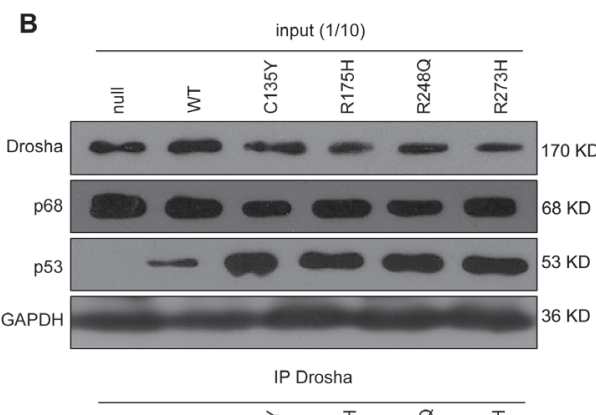

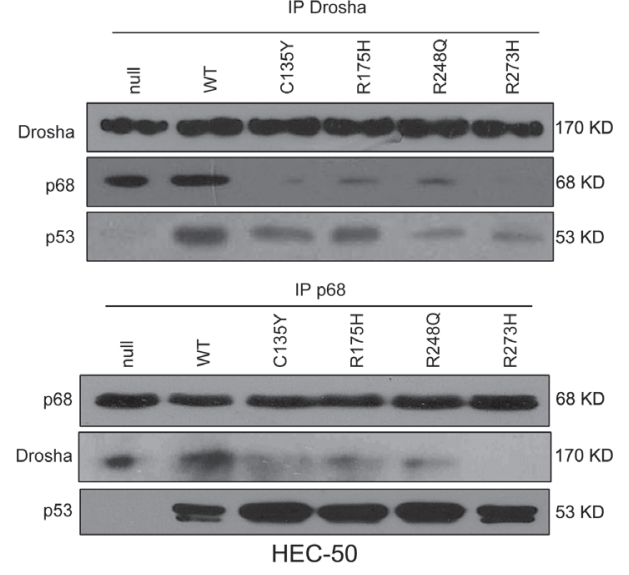

Figure 4: miRNA processing is deregulated by mutp53. A. p53-null HEC-50 cells were transfected with different p53 expression plasmids. The amount of pri-miR-26a-1 and pre-miR-26a-1 were examined ( $* * P<0.01 v s$ null, $* * * P<0.001 v s$ null). B. Immunoprecipitation (IP) assays were performed after transfection with different $\mathrm{p} 53$ expression plasmids. C. RNA-ChIP analysis. After transfection of p53-null HEC-50 cells with different $\mathrm{p} 53$ expression plasmids, endogenous proteins were immunoprecipitated by anti-p68 or anti-Drosha antibodies and subjected to RT-PCR analysis with miR-26a-1 (*P<0.05 vs null). 
In miRNA biogenesis, the pri-miRNAs are cleaved into pre-miRNAs by the nuclear RNase III, Drosha, and further processed to mature miRNAs by cytosolic Dicer. The Drosha complex comprises Drosha and multiple RNA-associated proteins, including p68 [22], which is required for the maturation of some, but not all miRNAs [23]. We therefore examined the effects of tumor-derived p53 mutants on miRNA processing by transfecting them into p53-null HEC-50 cells. p53 mutant cells had reduced pre-miR-26a-1 expression but no change in pri-miR-26a-1 expression. In contrast, WTp53 transfection increased premiR-26a-1 expression (Figure 4A). We next examined the effects of mutp53 expression on Drosha complex formation. Cells transfected with mutp53 had decreased interactions between Drosha and p68, while cells with WTp53 showed a modest increase in the Drosha-p68 association (Figure 4B). RNA-ChIP analysis revealed that cells with mutp53 had decreased associations between pri-miR-26a-1 and p68/Drosha (Figure 4C). These results suggest that tumor-derived p53 mutations might confer some different and opposite functions to the protein, leading to interference with miR-26a biogenesis by interference with Drosha/p68 complex assembly.

\section{EZH2 is the direct molecular target of miR-26a}

To further establish the effects of miR-26a on EZH2 expression, we examined HEC-1B cells transfected with miR-26a mimics and Ishikawa cells transfected with antimiR-26a. Compared with controls, transfection of miR26a mimics decreased EZH2 protein expression (Figure $5 \mathrm{~A})$. In contrast, EZH2 protein expression was increased in Ishikawa cells transfected with anti-miR-26a (Figure 5B). Neither treatment altered EZH2 mRNA expression (Figure 5A \& 5B).

TargetScan analysis indicated that the EZH2 gene contains a highly conserved miR-26a binding site on its 3'UTR (Figure 5C). To determine whether this putative miR-26a binding site was actually regulated by miR$26 \mathrm{a}$, we constructed vectors containing the wild-type or mutant 3'UTR of EZH2 fused with the firefly luciferase gene (Figure 5D). Vectors were cotransfected into NIH3T3 cells with miR-26a mimics or miR-26a control. Transfection efficiency was normalized by cotransfection with a Renilla reporter vector. As shown in Figure 5E, miR-26a decreased the relative luciferase activity of the wild-type EZH2 3'UTR vector by more than $65 \%$, whereas the reduction in luciferase activity of the mutant EZH2 3'UTR vector was not as dramatic. These results
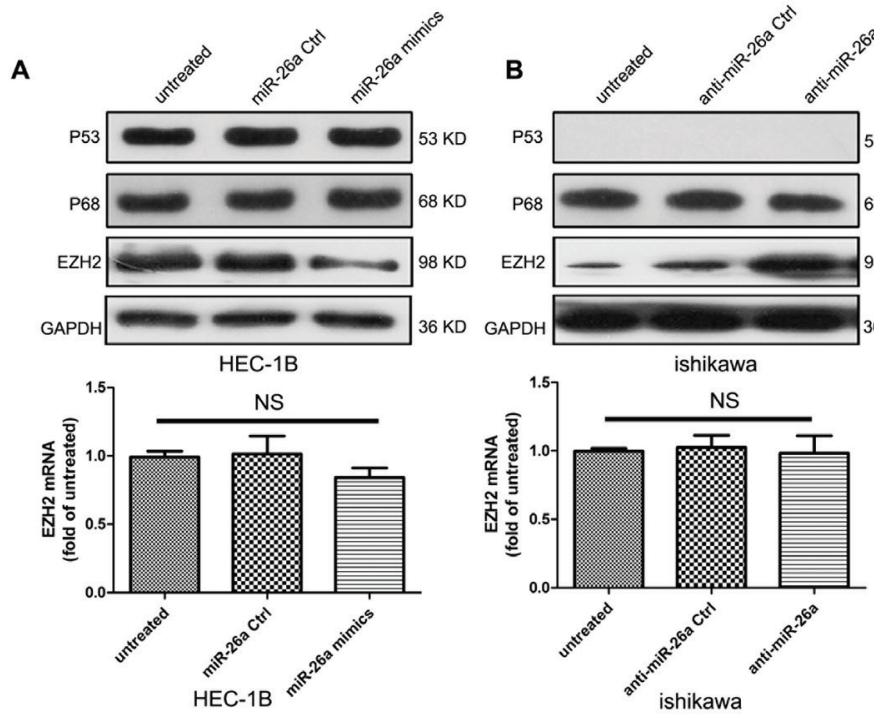

C

Human
Chimpanzee
Rhesus
Mouse
Rat

AACUUUGAAUAAAGAAUACUUGAACUU AACUUUGAAUAAAGAAUACUUGAACUU AACUUUGAAUAAAGAAUACUUGAACUU AAAUUUGAAUAAAGAAUACUUGAACUU AAAUUUGAAUAAAGAAUACUUGAACUU
D

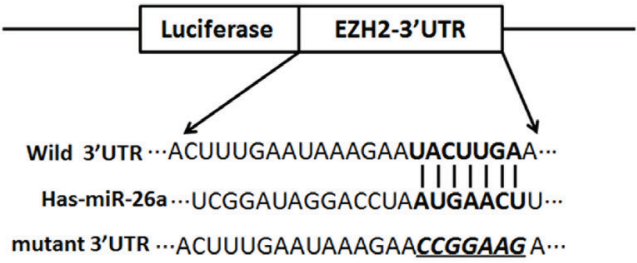

E

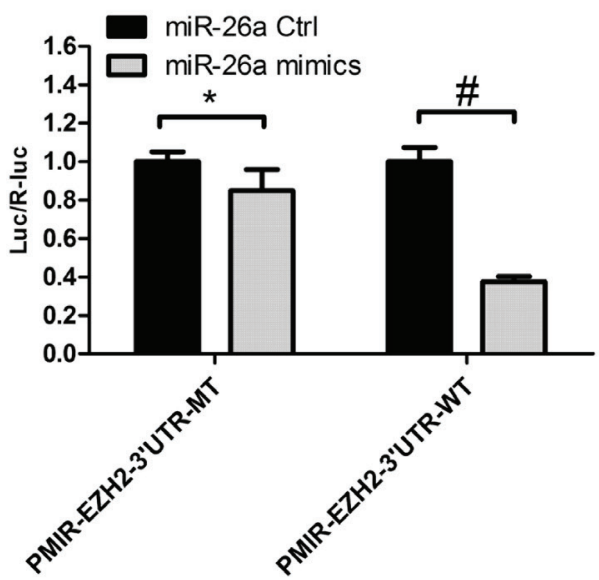

Figure 5: miR-26a negatively regulates EZH2 protein expression in EC cells. A. $\sim$ B. EZH2 protein and mRNA levels were measured in EC cells $72 \mathrm{~h}$ post-transfection by western blot assays (NS, not significant). C. Putative binding site of miR-26a on the EZH2 3'UTR in different species. The seed sequence is underlined. D. Sketch of the construction of pMIR-EZH2-3'UTR-WT or pMIR-EZH23'UTR-MT vectors. The mutant binding site is underlined and italicized. E. miR-26a mimics down-regulate luciferase activity controlled by wild-type EZH2 3'UTR ( $\left.{ }^{*} P=0.0122 ; \# P<0.001\right)$. 
suggest that miR-26a can bind to the 3'UTR of EZH2, and that $E Z H 2$ may be a downstream target of miR-26a in $\mathrm{EC}$ cells.

\section{miR-26a overexpression inhibits cell proliferation and invasion}

Mutp53 promotes cell migration, invasion and metastasis [24-29]. We found that stable knockdown of mutp53 in HEC-1B cell decreased invasion and colony formaton (supplementary figure 3 ). When miR-26a was re-expressed in p53 mutant HEC-1B cells with high EZH2 expression, it impaired the migration (Figure 6A $\& \mathrm{~B}, * * * P=0.0002$ ). and proliferation (Figure $6 \mathrm{C}$ ) of HEC-1B cells. Importantly, the effects on proliferation were observed after 3 days of transfection and not at earlier time points when the migration assays were performed, indicating the reduction in migration was not due to reduced cell numbers. miR-26a overexpression also inhibited the invasion of HEC-1B cells (Figure 6D \& 6E, $* * * P=0.0007)$ as well as invasion of poorly differentiated AN3CA cells with high EZH2 expression (Figure 6F, $* * * P$ $<0.0001)$. However, knockdown of miR-26a promoted Ishikawa cell invasion (Figure 6G \& 6H, ${ }^{* * *} P=0.0002$ ).

\section{miR-26a promotes mesenchymal-epithelial transition (MET) of EC cells}

To determine whether the miR-26a inhibition of cell invasion was due to induction of MET, we examined morphologIcal changes in HEC-1B cells transfected with miR-26a mimics. Overexpression of miR-26a induced a shift from a mesenchymal phenotype to a "paved stone" epithelial appearance, similar to changes seen in HEC1B cells with stable knockdown of mutp53 (Figure 7A). These morphological changes were accompanied by

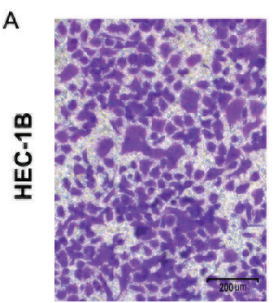

Untreated

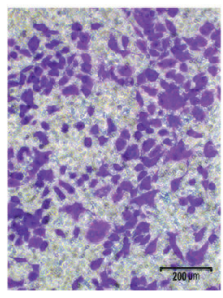

miR-26a Ctrl

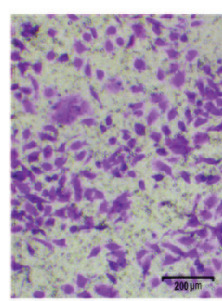

miR-26a Ctrl

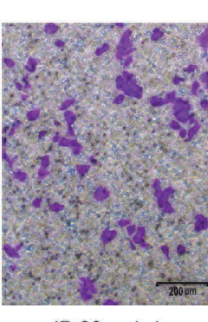

miR-26a mimics

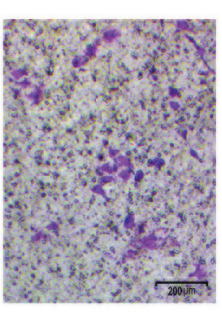

miR-26a mimics
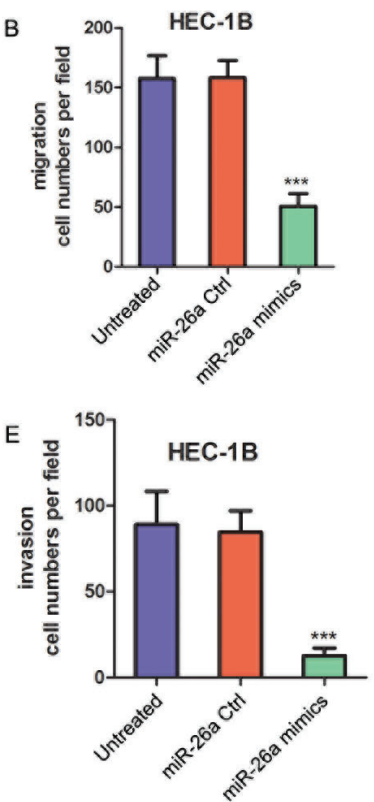
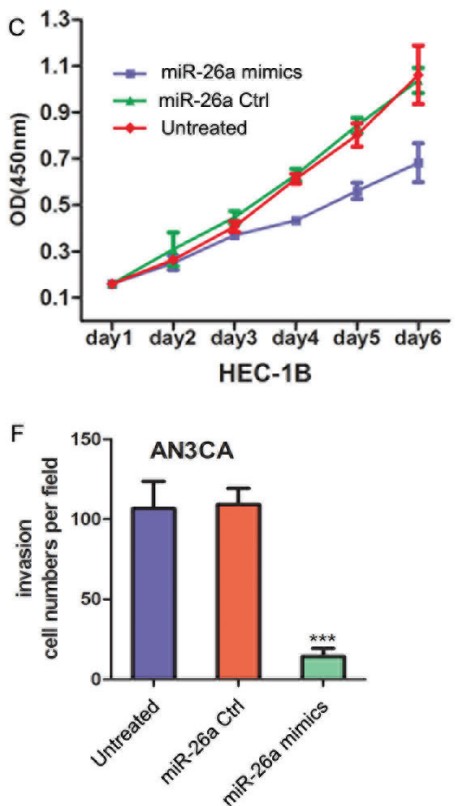

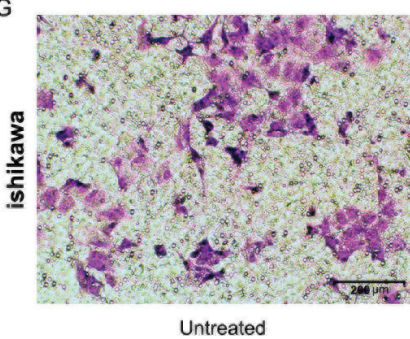

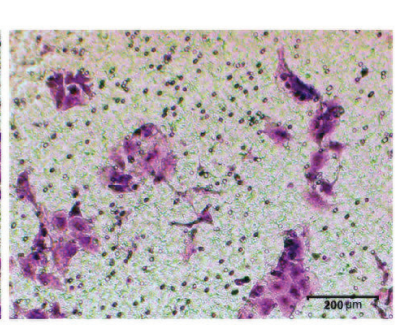

anti-miR-26a Ctrl

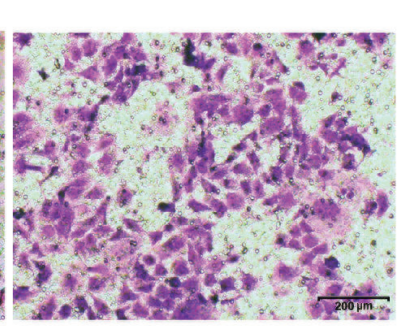

anti-miR-26a

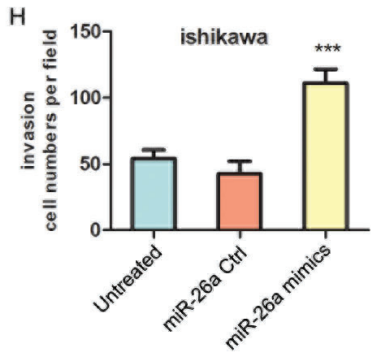

Figure 6: miR-26a impairs the EC cell migration and invasion. A. HEC-1B cells were transfected with miR-26a mimics, control or none for $48 \mathrm{~h}$ and seeded in a transwell filter. Migrated cells on the lower surface of the transwell filter were stained and counted after $24 \mathrm{~h}$. B. Quantification of A. Bars show mean \pm SD. ${ }^{* * *} P=0.0002$. C. CCK8 analysis of the growth of HEC-1B cells transfected with miR-26a mimics, control or none. D. HEC-1B cells after transfection seeded in a transwell filter paved with marigel matrix gel. Invasive cells on the lower surface of the transwell filter were stained and counted after $24 \mathrm{~h}$. E. Quantification of D. Bars show mean $\pm \mathrm{SD}$. $* * * P=$ 0.0007. F. The numbers of invasive cells of AN3CA. Bars show mean \pm SD. ${ }^{* * *} P<0.0001$. G. the invasion of Ishikawa after transfection was assayed in the same way. H. Quantification of G. Bars show mean \pm SD. ${ }^{* * *} P=0.0002$. 
the downregulation of mesenchymal genes, including $\mathrm{N}$-cadherin, Snail, and Vimentin, and increased expression of the epithelial marker E-cadherin (Figure 7B). When examined in detail with scanning laser confocal microscopy, exogenous miR-26a expression induced E-cadherin expression around cell-to-cell contacts and reduced Vimentin and $\mathrm{N}$-cadherin expression in the cytoplasm, while Snail expression was reduced in the nuclei (Figure 7C).

\section{miR-26a acts as a tumor suppressor in a mouse tumor xenograft model}

To further determine the role of miR-26a in the regulation of MET, we performed tumor xenograft experiments using HEC-1B cells. Subcutaneous tumor formation was observed in all nude mice 10 days after injection. During the 35 day follow-up period, the tumor volumes increased (Figure 8A). However, at 35 days, the size and weights of tumors were smaller in animals treated with LV-miR-26a than those that were untreated or treated with a LV-miR-26a control (Figure 8B, 8C \& 8D). Postmortem, tumor tissues were embedded in paraffin and stained with hematoxylin and eosin (H\&E) for histological examination (Figure 8E, left panel). Immunohistochemical
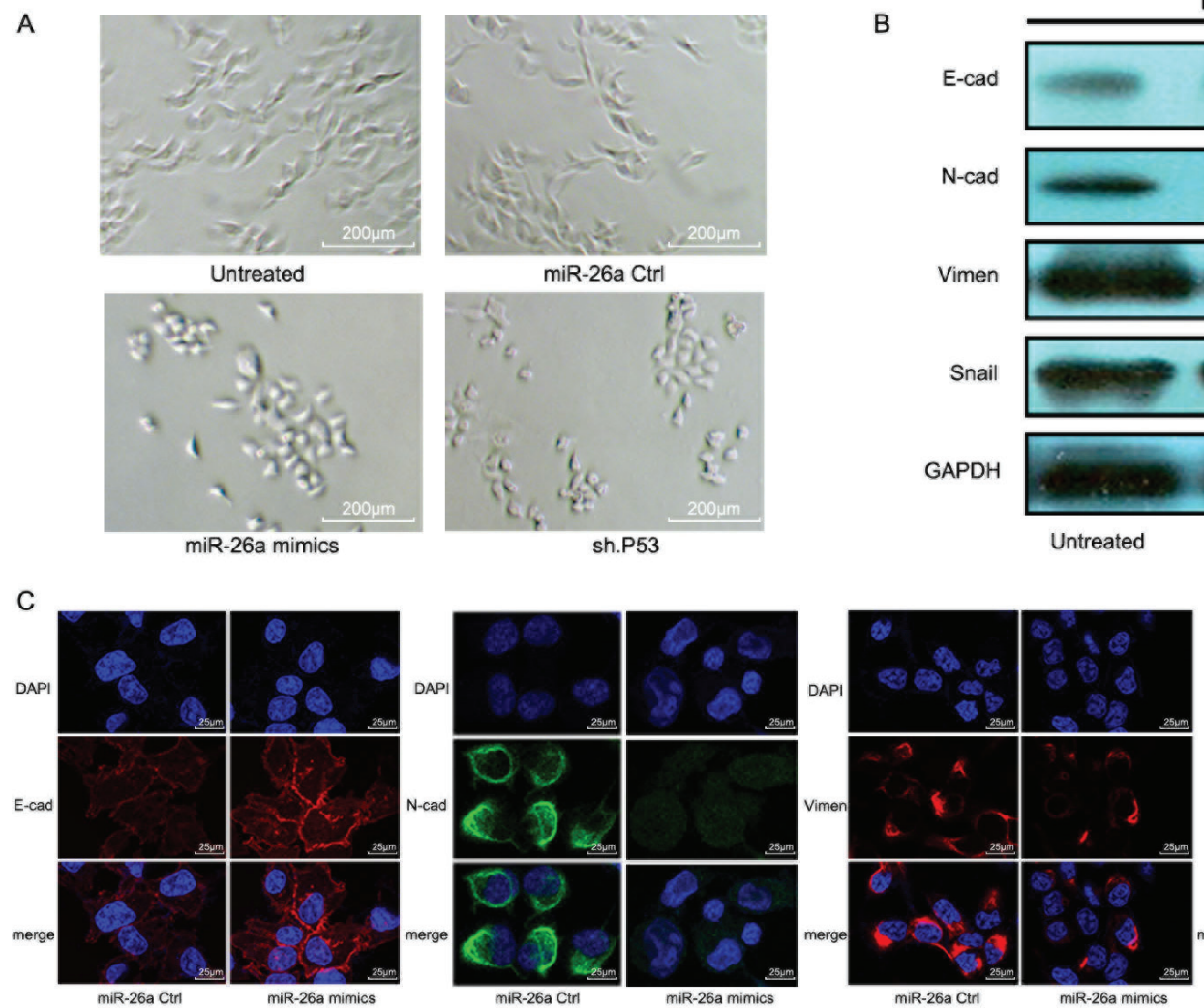

Figure 7: miR-26a promotes MET in HEC-1B cells. A. Morphological changes in HEC-1B cells after different treatments. B. EMT-related markers were examined in HEC-1B cells transfected with miR-26a mimics, miR-26a Ctrl mimics, or none. C. Changes in EMT markers were analyzed using scanning laser confocal microscopy after transfection with miR-26a mimics or control.
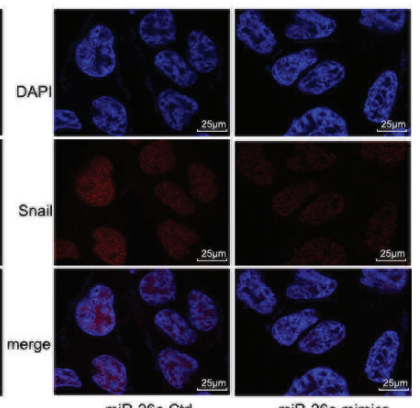

staining of Vimentin and E-cadherin revealed lower Vimentin expression and higher E-cadherin expression in LV-miR-26a tumors than in untreated or mock controls (Figure 8E, 8F \& 8G). Our in vitro studies suggested that $E Z H 2$ is the direct downstream target of miR-26a; therefore, we examined EZH2 protein expression in tumor tissues using IHC. EZH2 expression was reduced in the LV-miR-26a group compared to controls (Figure 8E \& $8 \mathrm{H})$, leading further support to the hypothesis that $E Z H 2$ is regulated by miR-26a. In addition, the LV-miR-26a group had lower proliferation indices than the controls (Figure $8 \mathrm{E} \& 8 \mathrm{I})$.

\section{Plasma miR- 26a expression may be a diagnostic tool for EC patients}

Expression of miR-26a was significantly reduced in type II EC serum compared to type I EC (Figure 9A). Moreover, patients with high miR-26a expression survived longer than patients with lower expression (Figure 9B).

\section{DISCUSSION}

Even when detected at an early-stage, most type II ECs already have distant metastasis. However, the

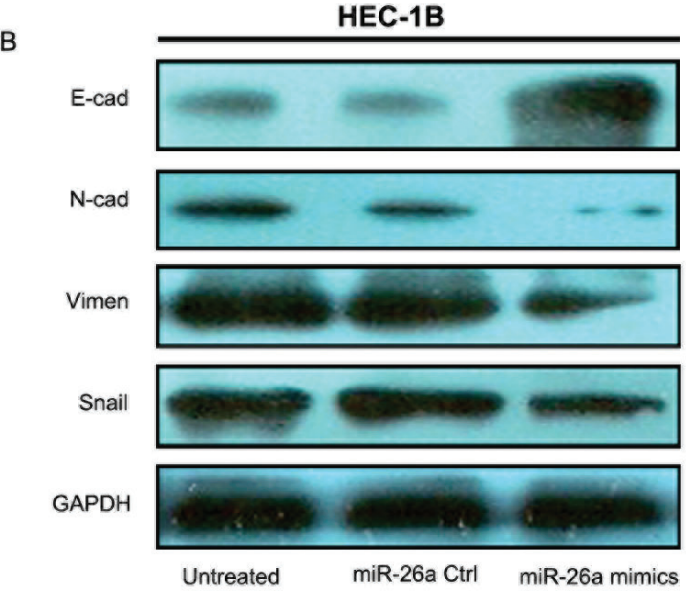

miR-26a Ctrl 
mechanism underlying metastasis is still unknown. The importance of p53 in preventing tumor formation is indicated by high rates of mutations in the p53 pathway in nearly all cancer types [30]. Integrated genomic characterization of EC indicates that recurrent p53 mutations are common in type II EC (90\%) [10], suggesting mutp53 promotes EC progression. Mice with endometrium-specific deletion of p53 exhibit histological changes that are identical to known precursor lesions for type II EC in humans and develop carcinomas exhibiting features of all type II subtypes [6].

It has been reported that WTp53 binds directly to the EZH2 promoter and represses EZH2 expression, leading to cell senescence [31]. These results differ from our finding that WTp53 inhibits EZH2 expression indirectly via miR-26a at the posttranscriptional level. Others
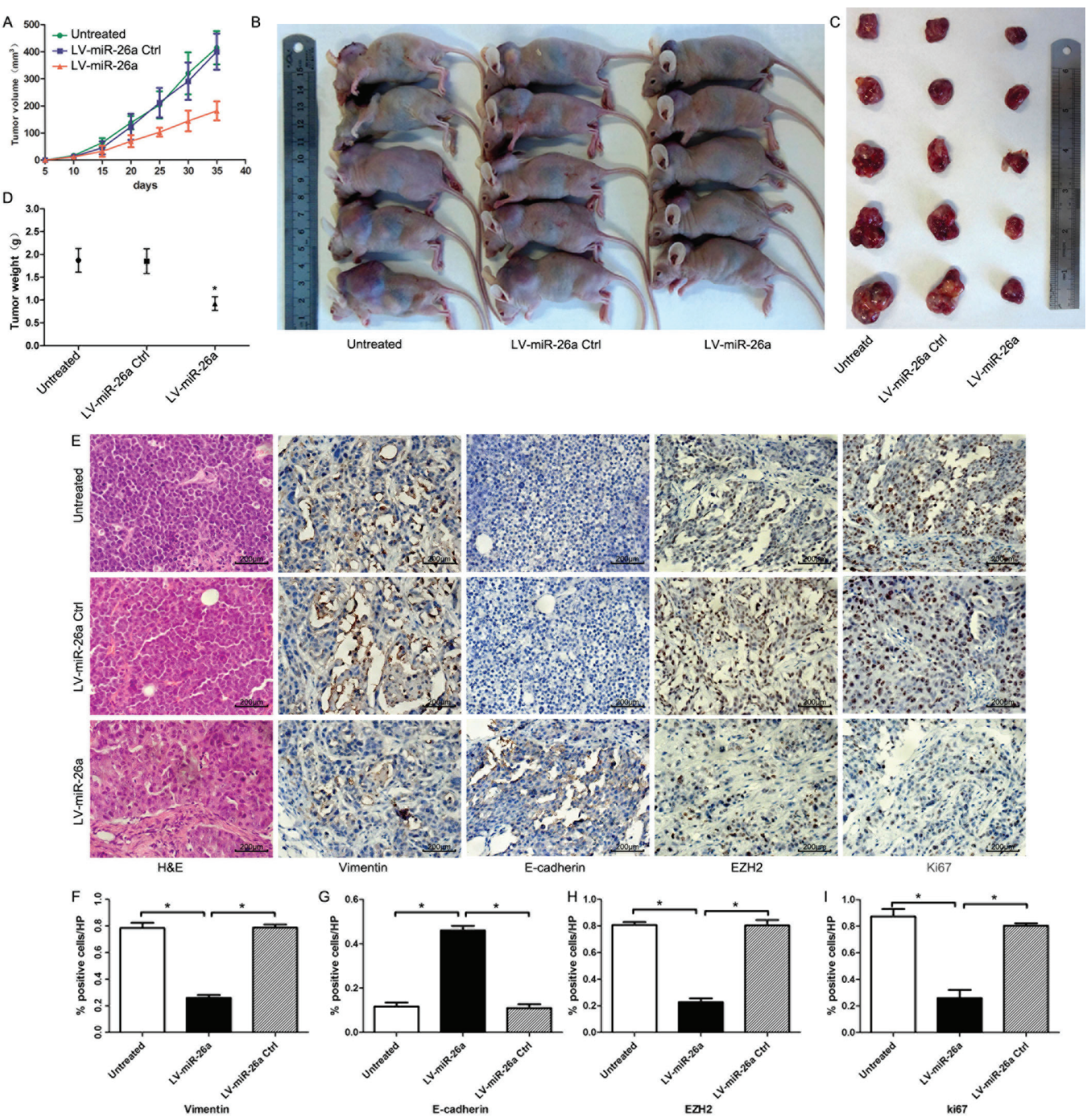

Figure 8: Tumorigenicity assay in nude mice. A. Tumor growth curve in nude mice. After tumor cells were injected subcutaneously into the neck of nude mice, the short and long diameters of the tumors were measured every 5 days and tumor volumes (mm3) were calculated. B. The nude mice with tumor formations. C. Photograph of tumors derived from LV-miR-26a, LV-miR-26a Ctrl or untransfected HEC-1B cells in nude mice. D. Weights of tumors. ${ }^{*} P<0.05$ as compared with either untreated group or LV-miR-26a Ctrl group. E. Representative HE staining histopathologic image of tumor tissues in mice (left panel). Vimentin, E-cadherin, EZH2, and Ki67 expression of tumors were detected by immunohistochemical technique (right panel). F. $\sim$ I. Quantification of Vimentin, E-cadherin, EZH2, and Ki67 expression in $\mathrm{E} .{ }^{*} P<0.01$. 
Table 1: Association analyses between the expression of EZH2 and clinicopathologic factors of endometrial carcinoma

\begin{tabular}{|c|c|c|c|c|c|c|}
\hline \multirow{2}{*}{ Variables } & \multirow{2}{*}{ Case no. } & \multicolumn{3}{|c|}{ EZH2 expression } & \multirow[b]{2}{*}{$\chi^{2}$} & \multirow{2}{*}{$P$-value } \\
\hline & & Negative & Low & High & & \\
\hline \multicolumn{7}{|l|}{ Age (year) } \\
\hline$<55$ & 61 & 28 & 19 & 14 & 1.959 & 0.376 \\
\hline$\geq 55$ & 33 & 12 & 9 & 12 & & \\
\hline \multicolumn{7}{|c|}{ Histological type } \\
\hline Type I & 60 & 37 & 17 & 6 & 33.062 & $<0.001$ \\
\hline Type II & 34 & 3 & 11 & 20 & & \\
\hline \multicolumn{7}{|c|}{ Histological grade } \\
\hline G1 & 58 & 34 & 17 & 7 & 26.518 & $<0.001$ \\
\hline $\mathrm{G} 2$ & 22 & 5 & 8 & 9 & & \\
\hline G3 & 14 & 1 & 3 & 10 & & \\
\hline \multicolumn{7}{|c|}{ FIGO stage } \\
\hline I-II & 67 & 35 & 22 & 10 & 19.545 & $<0.001$ \\
\hline III-IV & 27 & 5 & 6 & 16 & & \\
\hline \multicolumn{7}{|c|}{ Lymph node metastasis } \\
\hline $\mathrm{NO}$ & 73 & 36 & 21 & 16 & 12.334 & 0.002 \\
\hline Yes & 21 & 4 & 7 & 10 & & \\
\hline \multicolumn{7}{|c|}{ Depth of endometrial invasion } \\
\hline$\leq 50 \%$ & 73 & 36 & 21 & 16 & 7.520 & 0.023 \\
\hline$>50 \%$ & 21 & 4 & 7 & 10 & & \\
\hline \multicolumn{7}{|c|}{ p53 expression } \\
\hline Negative & 47 & 36 & 9 & 2 & 63.414 & $<0.001$ \\
\hline Low & 20 & 2 & 13 & 5 & & \\
\hline High & 27 & 2 & 6 & 19 & & \\
\hline
\end{tabular}

have found that mutp53, but not WTp53, is reduced in response to EZH2 knockdown [32]. However, DZNep (3-deazaneplanocin A) stabilizes WTp53 by reducing ubiquitin conjugation through USP10 upregulation, resulting in p53 accumulation and activation of its downstream target genes [33]. Consequently, WTp53 cancer cells are sensitive to DZNep treatment. Thus, the relationship between EZH2 and p53 may be complex and cell-type dependent.
Most somatic mutations $(82 \%)$ in p53 are single nucleotide missense substitutions located in the DNA binding doman (DBD), which encompasses p53 exons 5-8. Mutations in codons 248 and 273 are classified as DNA contact mutations, while alterations in codon 175 are considered conformational mutations [34]. However, no matter how these hot-spot mutants are classified, all have impaired sequence-specific DNA-binding capacity resulting in a loss of transcriptional activity [35-37].
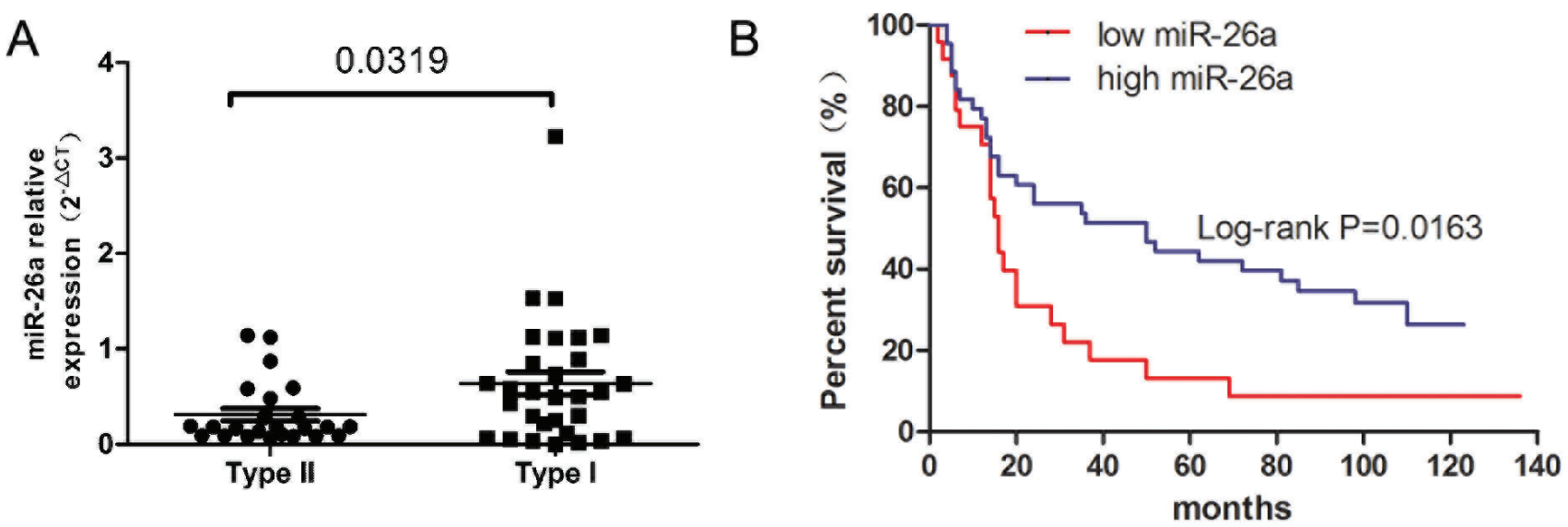

Figure 9: miR-26a expression and prognosis of EC patients. A. miR-26a expression was reduced in type II EC patient serum compared to type I. B. Kaplan-Meier overall survival curve according to miR-26a expression in EC patient serum (Log-rank $P=0.0136)$. 
Recent studies have shown that WTp53 induces miR-26a expression by directly binding to the $-500,-1500$, and -2000 regions of $m i R-26 a-1$ [20]. We failed to find mutp53 binding in these upstream regions suggesting that mutp53 does not suppress miR-26a expression via a dominant negative mechanism. Consistent with that finding, we also demonstrated that mutp53 has reduced DNA-binding ability. One limitation of our study is that we chose to examine only hot-spot p53 mutations; there may be other p53 mutations that have different effects.

We demonstrated that p53 mutations can induce EMT and increase the invasiveness of EC cells by regulating a large set of EMT-associated genes. More importantly, we provide an underlying mechanism for mutp53-enhanced metastasis: p53 mutations not only impair its ability to bind the promoter of miR-26a-1, but also impair p68-Drosha complex assembly and attenuate miR-26a-1 processing. Together, this results in a reduction in miR-26a expression and upregulation of EZH2 expression. Our results suggest that p53 mutations result in "gain-of-function" oncogenic properties that can contribute to cell proliferation, survival, and metastasis. Notably, the effects of mutp53 on EMT and cell invasion can be partially abolished by restoration of miR-26a expression. Re-expression of miR-26a may therefore inhibit tumor metastasis and progression, providing a potential therapeutic use in patients with EC.

mutp53 drives EMT via various signaling pathways, including the miR-130b-ZEB1 axis and Rab coupling protein (RCP)-dependent receptor recycling [9, 27]. At the molecular level, EMT occurs as a result of the activity of several transcription factors, including Twist, Snail, and ZEB1/2, which repress expression of the epithelial marker E-cadherin and promote expression of the mesenchymal markers N-cadherin and Vimentin. DAB2IP, which is negatively regulated by EZH2, is an important suppressor of EMT [38]. However, EMT initiation and regulation is still not fully understood.

We previously showed that DICER1, a key enzyme catalyzing miRNA biosynthesis, is expressed at lower levels in AN3CA than RL95-2, Ishikawa, or KLE cells (supplementary figure 2B) [39, 40]. We also showed that levels of Let-7b expression are lower in AN3CA cells than in RL95-2, Ishikawa, or KLE cells (supplementary figure 2C). Two recent studies showed that overexpression of Let- $7 \mathrm{~b}$ reduces EZH2 protein levels [41, 42]. These results may explain why AN3CA cells express high levels of $\mathrm{EZH} 2$ with undetectable p53 expression, but this requires further investigation.

In summary, we identified a mechanism by which mutp53 exerts oncogenic effects and promotes EMT in EC by disrupting p68-Drosha complex assembly and decreasing miR-26a production. This results in increased $\mathrm{EZH} 2$ expression and promotes EC tumor progression. Our results provide further evidence of the vital roles played by miRNAs in EC tumorigenesis. Although
miRNA-based therapeutics are still in their infancy, our findings suggest that miR-26a could be a potential target in the treatment of EC [43].

\section{MATERIALS AND METHODS}

\section{Cell culture}

The EC cell lines KLE, HEC-1B, and AN3CA were obtained from American Type Culture Collection (ATCC, Manassas, Va) and Ishikawa, SPEC-2 and p53-null HEC-50 were obtain from the Cell Bank of the Chinese Academy of Sciences (Shanghai, China). All cell lines were cultured in DMEM/F12 medium containing 10\% fetal bovine serum.

\section{Patients and samples}

Tissue samples for IHC and serum were obtained from 94 patients with EC and 30 patients with normal endometrium who underwent surgical resection at Department of Obstetrics and Gynecology, Shanghai General Hospital from 1997 to 2012, and each case had up to 15 years of clinical follow-up information. The project was approved by the Institutional Review Board of Shanghai General Hospital, and informed consent was obtained from all patients before the study.

\section{Reagents}

Synthetic, chemically modified short single- or double-stranded RNA oligonucleotides: miR-26a mimics, miR-26a control (Ctrl), anti-miR-26a, anti-miR-26a Ctrl, p68 siRNA (sip68), p53 siRNA (sip53), and EZH2 siRNA (siEZH2) were synthesized from Shanghai GenePharma Co.,Ltd. Commercial miR-26a expression Lentivirus and counterpart control vector were purchased from Shanghai GenePharma Co.,Ltd. Commercial p68 expression plasmid and sh.p53 plasmid carrying small hairpin RNA targeting p53 were purchased from Shanghai Gene-Chem Co., Ltd. Commercial mutp53 expression plasmids and wild-type p53 expression plasmid were constructed and provided by GuangZhou Biosicen Biotechnology CO., Ltd. All oligonucleotide sequences are listed in supplementary table 1 .

\section{Immunohistochemistry (IHC)}

Antibodies used for IHC were: EZH2 (5246; 1:50; CST), p53 (2527; 1:200; CST), Vimentin (5471; $1: 100 ;$ CST), E-cadherin (3195; 1:400; CST), and Ki67 (BM2889; 1:200; Boster). For evaluation of EZH2 and p53 IHC staining, the staining intensity was scored as 0 
(negative), 1 (weak), 2 (strong). The extent of staining was scored as $0(<25 \%), 1(25 \sim 75 \%)$, and $2(>75 \%)$. The final immunoreactivity scores were obtained by adding these two scores. Tissues having a final immunoreactivity score of 3 4 and 1 2 were considered to be high expression and low expression, respectively. Staining was scored independently by two pathologists without knowledge of the clinicopathological findings.

\section{RNA isolation and qRT- PCR}

Briefly, total RNA was extracted from cells and serum using TRIzol ${ }^{\circledR}$ and TRIzol ${ }^{\circledR}$ LS Reagent (Life Technologies, USA) following the supplier's instructions. All primers and reagents for mature miRNA analysis were purchased from Life Technologies according to manufacturer's instructions. U6 snRNA served as an endogenous control for normalization. Other specific primers for qRT- PCR are listed in supplementary table 2.

\section{Western blot analysis, ChIP and RNA-ChIP}

Total cell lysis and western blot analysis were performed as described previously using the following antibodies [44]: EZH2 (5246; 1:1000; CST), p53 (2527; 1:1000; CST), N-cadherin (13116; 1:1000; CST), E-cadherin ( $3195 ; 1: 1000 ;$ CST), Vimentin $(5741 ; 1: 1000$; CST), Snail (3879; 1:1000; CST) and GAPDH (56321; 1:2000; Epitomics), and anti-rabbit IgG (1:10000, Jackson). The ChIP assay was performed using the Pierce Agarose ChIP kit (Pierce; Thermo Scientific, Rockford, IL, USA) according to the manufacturer's protocol. The antibody used in ChIP analysis was p53 (2527; 1:200; CST). To amplify the potential p53-binding sites, specific primers for PCR were listed in supplementary table 2 . RNA-ChIP was performed as described previously [23, 45, 46]. Immunoprecipitation for RNA-ChIP was performed using the following antibodies: p68 (05-850; Upstate) and Drosha (ab12286; Abcam). Specific primers for RNA-ChIP had the following sequences: forward primer (5'-GCCCAATGGCATAGCAAGA-3') and reverse primer (5'-GGCCAGTCATGCTTACAGTCAC-3').

\section{Cell proliferation, migration and invasion assays}

Cell proliferation assays were performed as described previously [44]. Transwell invasion assays were performed according to the manufacturer's protocol (BD Biosciences, San Jose, CA, USA). Briefly, cells $\left(1 \times 10^{5}\right)$ transfected with different small nucleotides for $48 \mathrm{~h}$ were added to the upper chamber of transwell filters coated with matrigel (or none) in serum-free medium. The cells that invaded the lower chamber were stained with Crystal violet stain and counted after $24 \mathrm{~h}$ of incubation at $37^{\circ} \mathrm{C}$ with $5 \% \mathrm{CO} 2$. Photographs were taken at $24 \mathrm{~h}$ postmigration or postinvasion (magnification, $400 \times$ ). Each experimental group had two replicates, and three fields in each replicate were randomly chosen for quantification of invasive cells.

\section{Co-immunoprecipitation}

Co-immunoprecipitation was performed as described previously [21]. The following antibodies were used: anti-p53 (9282; 1:200; CST), anti-p68 (ab128928; 1:100; Abcam) and anti-Drosha (ab12286; 1:100, Abcam).

\section{Immunofluorescence}

Briefly, HEC-1B cells were seeded on the confocal laser dish at a density of $5 \times 10^{4}$ cells $/ \mathrm{ml}$ and cultured for $24 \mathrm{~h}$. The cultured cells were washed 3 times with PBS and fixed with 4\% paraformaldehyde (Sigma-Aldrich, St. Louis, USA) for $30 \mathrm{~min}$. After blocking, the cells were incubated first with anti-E-cadherin $(3195 ; 1: 100 ;$ CST), anti-N-cadherin(13116; 1:200; CST), anti-Vimentin (5741; 1:200; CST) or anti-Snail (ab180714; 1:50; abcam) antibody overnight at $4^{\circ} \mathrm{C}$, and then with $\mathrm{Cy} 3$-conjugated or FITC-conjugated goat anti-rabbit IgG antibody (1:200; Abcam, Cambridge, UK) and $5 \mathrm{mg} / \mathrm{ml}$ DAPI (SigmaAldrich) at room temperature for $30 \mathrm{~min}$. Then, the cells were observed under a laser scanning confocal microscope (Leica, Heidelberg, Germany) with emission wavelengths of $518 \mathrm{~nm}, 570 \mathrm{~nm}$, and $461 \mathrm{~nm}$.

\section{Construction of reporter plasmids and luciferase assay}

The wild-type 3'UTR of EZH2 was amplified using forward primer(5'-ATAGGCCGGCATAGACGC GTCATCTGCTACCTCCTCCCC-3', MluI) and reverse primer(5'-AAAGATCCTTTATTAAGCTTGATTCAAC AAGGACAAGTTCAAGTATTCTTTATTC-3', hindlII), and the counterpart mutant 3'UTR was amplified using forward primer(5'-ATAGGCCGGCATAGACGCGT CATCTGCTACCTCCTCCCC-3', MluI) and reverse primer(5'-AAAGATCCTTTATTAAGCTTGATTCA ACAAGGACAAGTCTTCCGGTTCTTTATTCAAA GTTGAAAAATG-3', hindlII) (The underlined primer sequence indicates the binding sites for MluI and hindIII). Amplicons were sub-cloned into MluI/hindlII sites of the pMIR-REPORT luciferase vector (Ambion) downstream of the luciferase gene to produce pMIR-EZH2-3'UTR-WT and pMIR-EZH2-3'UTR-MT, respectively. The luciferase reporter assay was performed as previously described [44]. Correct insertion was confirmed by gel electrophoresis and DNA sequencing. 


\section{Animal experiments}

Animal experiments were approved by the Ethics Committee for Animal Experimentation of Shanghai Jiaotong University and performed as described previously [44].

\section{Statistical analysis}

All statistical analysis were performed using SPSS 18.0 and GraphPad Prism. Bars show mean \pm SD and differences were evaluated using one-way ANOVA for 3 -group comparisons and $t$-tests for 2-group comparisons. The probability of $P<0.05$ was considered to be statistically significant. All experiments were repeated three times independently.

\section{ACKNOWLEDGMENTS}

The work was supported by National Natural Science Foundation of China (NO.81302251, NO.81172476, NO.81272885, and NO.81472427), and supported by Doctoral Innovation Fund Projects from Shanghai Jiao Tong University School of Medicine.

\section{CONFLICTS OF INTEREST}

None

\section{REFERENCES}

1. Bokhman JV. Two pathogenetic types of endometrial carcinoma. Gynecol Oncol. 1983; 15:10-17.

2. Arafa M, Somja J, Dehan P, Kridelka F, Goffin F, Boniver $\mathrm{J}$ and Delvenne P. Current concepts in the pathology and epigenetics of endometrial carcinoma. Pathology. 2010; 42:613-617.

3. Gehrig PA and Bae-Jump VL. Promising novel therapies for the treatment of endometrial cancer. Gynecol Oncol. 2010; 116:187-194.

4. Vousden $\mathrm{KH}$ and $\mathrm{Lu} \mathrm{X}$. Live or let die: the cell's response to p53. Nat Rev Cancer. 2002; 2:594-604.

5. Levine AJ and Oren M. The first 30 years of p53: growing ever more complex. Nat Rev Cancer. 2009; 9:749-758.

6. Wild PJ, Ikenberg K, Fuchs TJ, Rechsteiner M, Georgiev S, Fankhauser N, Noske A, Roessle M, Caduff R, Dellas A, Fink D, Moch H, Krek W and Frew IJ. p53 suppresses type II endometrial carcinomas in mice and governs endometrial tumour aggressiveness in humans. EMBO molecular medicine. 2012; 4:808-824.

7. Wang W, Cheng B, Miao L, Mei Y and Wu M. Mutant p53$\mathrm{R} 273 \mathrm{H}$ gains new function in sustained activation of EGFR signaling via suppressing miR-27a expression. Cell Death
Dis. 2013; 4:e574.

8. Weissmueller S, Manchado E, Saborowski M, Morris JPt, Wagenblast E, Davis CA, Moon SH, Pfister NT, Tschaharganeh DF, Kitzing T, Aust D, Markert EK, Wu J, Grimmond SM, Pilarsky C, Prives C, et al. Mutant p53 drives pancreatic cancer metastasis through cellautonomous PDGF receptor beta signaling. Cell. 2014; 157:382-394.

9. Dong P, Karaayvaz M, Jia N, Kaneuchi M, Hamada J, Watari H, Sudo S, Ju J and Sakuragi N. Mutant p53 gain-offunction induces epithelial-mesenchymal transition through modulation of the miR-130b-ZEB1 axis. Oncogene. 2013; 32:3286-3295.

10. Kandoth C, Schultz N, Cherniack AD, Akbani R, Liu Y, Shen H, Robertson AG, Pashtan I, Shen R, Benz CC, Yau C, Laird PW, Ding L, Zhang W, Mills GB, Kucherlapati $\mathrm{R}$, et al. Integrated genomic characterization of endometrial carcinoma. Nature. 2013; 497:67-73.

11. Wang L, Jin Q, Lee JE, Su IH and Ge K. Histone H3K27 methyltransferase Ezh2 represses Wnt genes to facilitate adipogenesis. Proc Natl Acad Sci U S A. 2010; 107:73177322.

12. Gao SB, Zheng QF, Xu B, Pan CB, Li KL, Zhao Y, Zheng QL, Lin X, Xue LX and Jin GH. EZH2 represses target genes through H3K27-dependent and H3K27-independent mechanisms in hepatocellular carcinoma. Mol Cancer Res. 2014; 12:1388-1397.

13. Zhou Z, Gao J, Popovic R, Wolniak K, Parimi V, Winter JN, Licht JD and Chen YH. Strong expression of EZH2 and accumulation of trimethylated H3K27 in diffuse large B-cell lymphoma (DLBCL) independent of cell of origin and EZH2 codon 641 mutation. Leukemia \& lymphoma. 2015:1-19.

14. Varambally S, Dhanasekaran SM, Zhou M, Barrette TR, Kumar-Sinha C, Sanda MG, Ghosh D, Pienta KJ, Sewalt RG, Otte AP, Rubin MA and Chinnaiyan AM. The polycomb group protein EZH2 is involved in progression of prostate cancer. Nature. 2002; 419:624-629.

15. Kleer CG, Cao Q, Varambally S, Shen R, Ota I, Tomlins SA, Ghosh D, Sewalt RG, Otte AP, Hayes DF, Sabel MS, Livant D, Weiss SJ, Rubin MA and Chinnaiyan AM. EZH2 is a marker of aggressive breast cancer and promotes neoplastic transformation of breast epithelial cells. Proc Natl Acad Sci U S A. 2003; 100:11606-11611.

16. Bachmann IM, Halvorsen OJ, Collett K, Stefansson IM, Straume O, Haukaas SA, Salvesen HB, Otte AP and Akslen LA. EZH2 expression is associated with high proliferation rate and aggressive tumor subgroups in cutaneous melanoma and cancers of the endometrium, prostate, and breast. Journal of clinical oncology : official journal of the American Society of Clinical Oncology. 2006; 24:268-273.

17. Zhou J, Roh JW, Bandyopadhyay S, Chen Z, Munkarah AR, Hussein Y, Alosh B, Jazaerly T, Hayek K, Semaan A, Sood AK and Ali-Fehmi R. Overexpression of enhancer of 
zeste homolog 2 (EZH2) and focal adhesion kinase (FAK) in high grade endometrial carcinoma. Gynecol Oncol. 2013; 128:344-348.

18. Pietersen AM, Horlings HM, Hauptmann M, Langerod A, Ajouaou A, Cornelissen-Steijger P, Wessels LF, Jonkers J, van de Vijver MJ and van Lohuizen M. EZH2 and BMI1 inversely correlate with prognosis and TP53 mutation in breast cancer. Breast cancer research. 2008; 10:R109.

19. Schneider J, Rubio MP, Rodriguez-Escudero FJ, Seizinger BR and Castresana JS. Identification of p53 mutations by means of single strand conformation polymorphism analysis in gynaecological tumours: comparison with the results of immunohistochemistry. European journal of cancer. 1994; 30A:504-508.

20. Lezina L, Purmessur N, Antonov AV, Ivanova T, Karpova E, Krishan K, Ivan M, Aksenova V, Tentler D, Garabadgiu AV, Melino G and Barlev NA. miR-16 and miR-26a target checkpoint kinases Wee1 and Chk1 in response to p53 activation by genotoxic stress. Cell Death Dis. 2013; 4:e953.

21. Bates GJ, Nicol SM, Wilson BJ, Jacobs AM, Bourdon JC, Wardrop J, Gregory DJ, Lane DP, Perkins ND and Fuller-Pace FV. The DEAD box protein p68: a novel transcriptional coactivator of the p53 tumour suppressor. EMBO J. 2005; 24:543-553.

22. Gregory RI, Yan KP, Amuthan G, Chendrimada $\mathrm{T}$, Doratotaj B, Cooch $\mathrm{N}$ and Shiekhattar R. The Microprocessor complex mediates the genesis of microRNAs. Nature. 2004; 432:235-240.

23. Fukuda T, Yamagata K, Fujiyama S, Matsumoto T, Koshida I, Yoshimura K, Mihara M, Naitou M, Endoh H, Nakamura T, Akimoto C, Yamamoto Y, Katagiri T, Foulds C, Takezawa S, Kitagawa H, et al. DEAD-box RNA helicase subunits of the Drosha complex are required for processing of rRNA and a subset of microRNAs. Nature cell biology. 2007; 9:604-611.

24. Subramanian M, Francis $\mathrm{P}$, Bilke S, Li XL, Hara T, Lu X, Jones MF, Walker RL, Zhu Y, Pineda M, Lee C, Varanasi L, Yang Y, Martinez LA, Luo J, Ambs S, et al. A mutant p53/let-7i-axis-regulated gene network drives cell migration, invasion and metastasis. Oncogene. 2014.

25. Arjonen A, Kaukonen R, Mattila E, Rouhi P, Hognas G, Sihto H, Miller BW, Morton JP, Bucher E, Taimen P, Virtakoivu R, Cao Y, Sansom OJ, Joensuu H and Ivaska J. Mutant p53-associated myosin-X upregulation promotes breast cancer invasion and metastasis. The Journal of clinical investigation. 2014; 124:1069-1082.

26. Neilsen PM, Noll JE, Mattiske S, Bracken CP, Gregory PA, Schulz RB, Lim SP, Kumar R, Suetani RJ, Goodall GJ and Callen DF. Mutant p53 drives invasion in breast tumors through up-regulation of miR-155. Oncogene. 2013; 32:2992-3000.

27. Muller PA, Trinidad AG, Timpson P, Morton JP, Zanivan S, van den Berghe PV, Nixon C, Karim SA, Caswell PT, Noll JE, Coffill CR, Lane DP, Sansom OJ, Neilsen PM,
Norman JC and Vousden KH. Mutant p53 enhances MET trafficking and signalling to drive cell scattering and invasion. Oncogene. 2013; 32:1252-1265.

28. Noll JE, Jeffery J, Al-Ejeh F, Kumar R, Khanna KK, Callen DF and Neilsen PM. Mutant p53 drives multinucleation and invasion through a process that is suppressed by ANKRD11. Oncogene. 2012; 31:2836-2848.

29. Muller PA, Caswell PT, Doyle B, Iwanicki MP, Tan EH, Karim S, Lukashchuk N, Gillespie DA, Ludwig RL, Gosselin P, Cromer A, Brugge JS, Sansom OJ, Norman JC and Vousden KH. Mutant p53 drives invasion by promoting integrin recycling. Cell. 2009; 139:1327-1341.

30. Hollstein M, Sidransky D, Vogelstein B and Harris CC. p53 mutations in human cancers. Science. 1991; 253:49-53.

31. Tang X, Milyavsky M, Shats I, Erez N, Goldfinger N and Rotter V. Activated p53 suppresses the histone methyltransferase EZH2 gene. Oncogene. 2004; 23:57595769.

32. Seward S, Semaan A, Qazi AM, Gruzdyn OV, Chamala S, Bryant CC, Kumar S, Cameron D, Sethi S, Ali-Fehmi R, Morris R, Bouwman DL, Munkarah AR, Weaver DW, Gruber SA and Batchu RB. EZH2 blockade by RNA interference inhibits growth of ovarian cancer by facilitating re-expression of p21(waf1/cip1) and by inhibiting mutant p53. Cancer Lett. 2013; 336:53-60.

33. Cheng LL, Itahana Y, Lei ZD, Chia NY, Wu Y, Yu Y, Zhang SL, Thike AA, Pandey A, Rozen S, Voorhoeve PM, Yu Q, Tan PH, Bay BH, Itahana K and Tan P. TP53 genomic status regulates sensitivity of gastric cancer cells to the histone methylation inhibitor 3-deazaneplanocin A (DZNep). Clin Cancer Res. 2012; 18:4201-4212.

34. Hainaut $P$ and Hollstein M. p53 and human cancer: the first ten thousand mutations. Advances in cancer research. 2000; 77:81-137.

35. Bullock AN, Henckel J and Fersht AR. Quantitative analysis of residual folding and DNA binding in mutant p53 core domain: definition of mutant states for rescue in cancer therapy. Oncogene. 2000; 19:1245-1256.

36. Epstein CB, Attiyeh EF, Hobson DA, Silver AL, Broach JR and Levine AJ. p53 mutations isolated in yeast based on loss of transcription factor activity: similarities and differences from p53 mutations detected in human tumors. Oncogene. 1998; 16:2115-2122.

37. Kern SE, Kinzler KW, Baker SJ, Nigro JM, Rotter V, Levine AJ, Friedman P, Prives C and Vogelstein B. Mutant p53 proteins bind DNA abnormally in vitro. Oncogene. 1991; 6:131-136.

38. Min J, Zaslavsky A, Fedele G, McLaughlin SK, Reczek EE, De Raedt T, Guney I, Strochlic DE, Macconaill LE, Beroukhim R, Bronson RT, Ryeom S, Hahn WC, Loda M and Cichowski K. An oncogene-tumor suppressor cascade drives metastatic prostate cancer by coordinately activating Ras and nuclear factor-kappaB. Nat Med. 2010; 16:286294. 
39. Li BL, Lu C, Lu W, Yang TT, Qu J, Hong X and Wan $\mathrm{XP}$. miR-130b is an EMT-related microRNA that targets DICER1 for aggression in endometrial cancer. Med Oncol. 2013; 30:484.

40. Zighelboim I, Reinhart AJ, Gao F, Schmidt AP, Mutch DG, Thaker PH and Goodfellow PJ. DICER1 expression and outcomes in endometrioid endometrial adenocarcinoma. Cancer. 2011; 117:1446-1453.

41. Tzatsos A, Paskaleva P, Lymperi S, Contino G, Stoykova $\mathrm{S}$, Chen Z, Wong KK and Bardeesy N. Lysine-specific demethylase 2B (KDM2B)-let-7-enhancer of zester homolog $2(\mathrm{EZH} 2)$ pathway regulates cell cycle progression and senescence in primary cells. J Biol Chem. 2011; 286:33061-33069.

42. Karoopongse E, Yeung C, Byon J, Ramakrishnan A, Holman ZJ, Jiang PY, Yu Q, Deeg HJ and Marcondes AM. The KDM2B- let-7b -EZH2 axis in myelodysplastic syndromes as a target for combined epigenetic therapy. PLoS One. 2014; 9:e107817.

43. Kota J, Chivukula RR, O'Donnell KA, Wentzel EA, Montgomery CL, Hwang HW, Chang TC, Vivekanandan P, Torbenson M, Clark KR, Mendell JR and Mendell JT. Therapeutic microRNA delivery suppresses tumorigenesis in a murine liver cancer model. Cell. 2009; 137:1005-1017.

44. Jiang F, Liu T, He Y, Yan Q, Chen X, Wang H and Wan X. MiR-125b promotes proliferation and migration of type II endometrial carcinoma cells through targeting TP53INP1 tumor suppressor in vitro and in vivo. BMC cancer. 2011; 11:425.

45. Suzuki HI, Yamagata K, Sugimoto K, Iwamoto T, Kato S and Miyazono K. Modulation of microRNA processing by p53. Nature. 2009; 460:529-533.

46. Ni JQ, Liu LP, Hess D, Rietdorf J and Sun FL. Drosophila ribosomal proteins are associated with linker histone $\mathrm{H} 1$ and suppress gene transcription. Genes \& development. 2006; 20:1959-1973. 